\title{
The influence of stage at diagnosis and molecular subtype on breast cancer patient survival: a hospital-based multi-center study
}

Tingting Zuo', Hongmei Zeng ${ }^{1}$, Huichao Li², Shuo Liu², Lei Yang² ${ }^{2}$ Changfa Xia', Rongshou Zheng ${ }^{1}$, Fei Ma ${ }^{3}$, Lifang Liư ${ }^{4}$, Ning Wang ${ }^{2}$, Lixue Xuan ${ }^{5^{*}}$ and Wanqing Chen ${ }^{1^{*}}$

\begin{abstract}
Background: Stage at diagnosis and molecular subtype are important clinical factors associated with breast cancer patient survival. However, subgroup survival data from a large study sample are limited in China. To estimate the survival differences among patients with different stages and various subtypes of breast cancer, we conducted a hospital-based multi-center study on breast cancer in Beijing, China.

Methods: All resident patients diagnosed with primary, invasive breast cancer between January 1, 2006 and December 31, 2010 from four selected hospitals in Beijing were included and followed up until December 31, 2015. Hospitalbased data of stage at diagnosis, hormone receptor status, and selected clinical characteristics, including body mass index (BMI), menopausal status, histological grade, and histological type, were collected from the medical records of the study subjects. Overall survival (OS) and cancer-specific survival (CSS) were estimated. Cox proportional hazards models were employed to evaluate the associations of stage at diagnosis and molecular subtype with patient survival.

Results: The 5-year OS and CSS rates for all patients were $89.4 \%$ and $90.3 \%$. Survival varied by stage and molecular subtype. The 5-year OS rates for patients with stage I, II, III, and IV diseases were 96.5\%, 91.6\%, 74.8\%, and 40.7\%, respectively, and the corresponding estimates of 5 -year CSS rates were $97.1 \%, 92.6 \%, 75.6 \%$, and $42.7 \%$, respectively. The 5-year OS rates for patients with luminal A, luminal B, HER2, and triple-negative subtypes of breast cancer were $92.6 \%, 88.4 \%, 83.6 \%$, and 82.9\%, respectively, and the corresponding estimates of 5-year CSS rates were 93.2\%, 89.1\%, $85.4 \%$, and $83.5 \%$, respectively. Multivariate analysis showed that stage at diagnosis and molecular subtype were important prognostic factors for breast cancer.

Conclusions: Survival of breast cancer patients varied significantly by stage and molecular subtype. Cancer screening is encouraged for the early detection and early diagnosis of breast cancer. More advanced therapies and health care policies are needed on HER2 and triple-negative subtypes.
\end{abstract}

Keywords: Breast cancer, Stage, Molecular subtype, Survival, China

\section{Background}

Breast cancer is the most common cancer in women of China, accounting for $15 \%$ of all new cancers in women

\footnotetext{
*Correspondence: xuanlx@hotmail.com; chenwq@cicams.ac.cn

${ }^{1}$ National Office for Cancer Prevention and Control \& National Central

Cancer Registry, National Cancer Center/Cancer Hospital, Chinese

Academy of Medical Sciences and Peking Union Medical College,

Beijing 100021, P. R. China

${ }^{5}$ Department of Breast Surgery, National Cancer Center/Cancer Hospital, Chinese Academy of Medical Sciences and Peking Union Medical College, Beijing 100021, P. R. China

Full list of author information is available at the end of the article
}

in 2015 [1], and women in urban areas had higher incidences than those in rural areas [2]. In Beijing, the capital and one of the largest cities of China, new breast cancer cases accounted for $22 \%$ of all new cancer cases in women between 2008 and 2012 [3]. In recent years, partly due to the changes in reproduction factors (e.g., nulliparity, mean number of children, age at first birth, and breastfeeding), the increasing use of hormone therapy and oral contraceptives, and more westernized dietary habits $[4$, 
$5]$, there were increasing trends of breast cancer incidence and mortality in China [1, 6].

Patient survival is a valuable medical indicator in evaluating the effectiveness and progress of breast cancer control. Stage at diagnosis is a key prognostic factor for breast cancer [7]. The disparities in breast cancer patient survival between Europe and the United States (US) were mainly explained by the lower proportion of advanced breast cancers in the US than in Europe [8]. Furthermore, breast cancer is a heterogeneous disease with distinct biological features, clinical behaviors, treatment responses, and outcomes according to its biological subtypes $[9,10]$. However, in-depth analyses on survival have often been single-center studies with limited representativeness of the population $[11,12]$. In China, few studies based on cancer registration data reported survival by different molecular subtypes of breast cancer [13].

In the present study, we conducted a multi-center, hospital-based study on breast cancer patient survival in Beijing, China. Meanwhile, using both active and passive follow-up systems of the population-based Beijing cancer registry, we were able to retrieve the information on the exact vital status of the study patients. We systematically analyzed breast cancer patient survival combining information of stage and molecular subtype with a large sample size, which will help us know the influence of related factors on breast cancer patient survival better.

\section{Methods}

\section{Study population}

All the Beijing residents who were newly diagnosed with breast cancer between January 1, 2006 and December 31, 2010 at four well-established hospitals were selected. The four involved hospitals were Cancer Hospital/Chinese Academy of Medical Sciences, Peking University Cancer Hospital, Beijing Obstetrics and Gynecology Hospital, and Shunyi Maternal and Child Health Care Hospital. Three of them were tertiary-level facilities, and one was secondary-level facility. Tertiary-level hospitals refer to the facilities that provide high-level medical and health care services to several districts with more hospital beds. Secondary-level hospitals have relatively less hospital beds and provide health care services to several communities. All female patients with primary invasive breast cancer were included in the final analysis. Exclusion criteria were as follows: male patients, non-invasive cancer, in situ cancer, or unknown vital status.

\section{Clinical data collection}

Personal and clinical information on name, address, age, date of diagnosis, height, weight, menopausal status, histological grade, histological type, stage at diagnosis, estrogen receptor (ER) status, progesterone receptor
(PR) status, human epidermal growth factor receptor 2 (HER2) status, and fluorescence in situ hybridization (FISH) results were abstracted from the medical records archived at the involved hospitals by trained investigators. Cancer staging was recorded according to the 7th edition of the American Joint Committee on Cancer (AJCC) criteria [14]. Molecular subtype was classified as luminal A (ER+ and/or PR+, HER2-), luminal B (ER+ and/or PR+, HER2+), HER2 (ER-, PR-, HER2+), triple-negative (ER-, PR-, HER2-) [15]. We defined HER2(-) or HER2(+) as negative expression, HER2(2+) as borderline expression, and HER2(3+) as positive expression. The cases with HER2 borderline expression would be further classified with FISH test.

\section{Follow-up}

The detailed follow-up data of selected patients were collected from the database of Beijing cancer registry. The registry archives all newly diagnosed cancer patients' records from all levels of clinics and hospitals, health insurance databases, death surveillance databases, the database of the basic medical insurances for urban residents, and the new-rural cooperative medical system. The registry routinely uses both active and passive follow-up methods to identify the survival statuses of cancer patients since the date of diagnosis. Passive follow-up was conducted by linking cancer registration records to the Beijing vital statistical database. The exact cause of death would be recorded in the death certification report when the patient died. Once the patient's personal identification record did not match with the Beijing vital statistical database, the registry would use active follow-up methods including home visits or telephone contact to retrieve his/her exact survival information and cause of deaths. All the patients were followed up until December 31, 2015.

\section{Statistical analysis}

Overall survival (OS) was defined as the time from diagnosis to death from any cause. Cancer-specific survival (CSS) was the time from diagnosis to death due to breast cancer. Data were censored if no endpoint event was observed during the study period. OS and CSS were estimated with the life-table method using the log-rank test for the detection of observed differences. Associations of breast cancer stage and molecular subtype with clinicopathologic features were examined using one-way analysis of variance (ANOVA) tests for continuous variables, and Chi square or Fisher exact test was used for categorical variables. Multivariable Cox proportional hazards models were employed to evaluate the associations between key prognostic factors, including stage at diagnosis, molecular subtype, and other mentioned factors, and survival outcome. Hazard 
ratios (HRs) were adjusted for age, body mass index (BMI), menopausal status, histological grade, histological type, cancer stage, and molecular subtype. All statistical analyses were conducted using SAS software version 9.2 (SAS Institute Inc, Cary, NC, USA).

\section{Results}

\section{Demographic and clinical characteristics of patients}

A total of 5044 patients diagnosed between 2006 and 2010 were identified, covering about $40.9 \%$ of all newly diagnosed breast cancer cases reported to the Beijing cancer registry. Detailed clinical information of these patients was collected. Among these patients, 404 were excluded for the following reasons: male $(n=16)$, noninvasive or in situ breast cancer $(n=135)$, unknown vital status $(n=249)$, and unknown cause of death $(n=4)$. A total of 4640 female patients with primary, invasive breast cancer were selected.

BMI $(P<0.01)$, menopausal status $(P=0.03)$, histological grade $(P<0.01)$, and molecular subtype $(P<0.01)$ showed significant differences by stage at diagnosis (Table 1). Patients with late-stage (stage III and stage IV) tumors were more likely to be triple-negative, at postmenopausal status, and with high BMI than those with early-stage (stage I and stage II) tumors.

Age $(P=0.01)$, menopausal status $(P<0.01)$, stage $(P<0.01)$, histological grade $(P<0.01)$, and histological type $(P<0.01)$ showed significant differences by molecular subtype (Table 2). The average age of patients with luminal A subtype of breast cancer was elder than the patients with other subtypes $(P=0.01)$. Patients with HER2 subtype were more likely to be postmenopausal, at late stage (III and IV), and had ductal breast cancer than patients with other subtypes (all $P<0.01$ ). Patients with triple-negative tumors tended to have poorly differentiated tumor and at advanced stage (III and IV) compared with patients with luminal $\mathrm{A}$ and luminal $\mathrm{B}$ subtypes (all $P<0.01)$.

\section{OS and CSS by stage and molecular subtype}

The median follow-up time was 79.0 months, ranging from 0.3 to 119.9 months. Of the 4640 female breast cancer patients, 3976 (85.7\%) were alive, and 664 (14.3\%) died before December 31, 2015. The 5-year OS rate was

Table 1 Characteristics of breast cancer patients by stage at diagnosis

\begin{tabular}{|c|c|c|c|c|c|c|c|}
\hline \multirow[t]{2}{*}{ Characteristic } & \multirow[t]{2}{*}{ Overall } & \multicolumn{5}{|l|}{ Stage } & \multirow[t]{2}{*}{$P$ value $^{b}$} \\
\hline & & I & II & III & IV & Unknown ${ }^{a}$ & \\
\hline Total & 4640 & 1334 & 2180 & 573 & 100 & 453 & \\
\hline Age (years) & $52.9 \pm 11.3$ & $53.1 \pm 11.5$ & $52.9 \pm 11.3$ & $52.6 \pm 11.0$ & $53.3 \pm 11.0$ & $55.7 \pm 13.6$ & 0.85 \\
\hline BMI & $25.0 \pm 3.8$ & $24.5 \pm 3.6$ & $25.2 \pm 3.9$ & $25.5 \pm 4.0$ & $25.0 \pm 3.5$ & $25.2 \pm 3.9$ & $<0.01$ \\
\hline Menopausal status & & & & & & & 0.03 \\
\hline Premenopausal & $2017(43.5)$ & $616(46.2)$ & $956(43.9)$ & $244(42.6)$ & $36(36.0)$ & $165(36.4)$ & \\
\hline Postmenopausal & $2510(54.1)$ & $691(51.8)$ & $1175(53.9)$ & $318(55.5)$ & $62(62.0)$ & $264(58.3)$ & \\
\hline Unknown ${ }^{a}$ & $113(2.4)$ & $27(2.0)$ & $49(2.2)$ & $11(1.9)$ & $2(2.0)$ & $24(5.3)$ & \\
\hline Histological grade & & & & & & & $<0.01$ \\
\hline Well differentiated & $349(7.5)$ & $147(11.0)$ & $136(6.2)$ & $20(3.5)$ & $5(5.0)$ & $41(9.1)$ & \\
\hline Moderately differentiated & $2549(54.9)$ & $714(53.5)$ & $1257(57.7)$ & $311(54.3)$ & $48(48.0)$ & $219(48.3)$ & \\
\hline Poorly differentiated & 899 (19.4) & $224(16.8)$ & $461(21.1)$ & $140(24.4)$ & $15(15.0)$ & $59(13.0)$ & \\
\hline Unknown ${ }^{a}$ & $843(18.2)$ & $249(18.7)$ & $326(15.0)$ & $102(17.8)$ & $32(32.0)$ & $134(29.6)$ & \\
\hline Histological type & & & & & & & 0.28 \\
\hline Ductal & $4031(86.9)$ & $1161(87.0)$ & $1928(88.4)$ & $509(88.8)$ & $88(88.0)$ & $345(76.2)$ & \\
\hline Lobular & $149(3.2)$ & $43(3.2)$ & $60(2.8)$ & $23(4.0)$ & $3(3.0)$ & $20(4.4)$ & \\
\hline Others & $460(9.9)$ & $130(9.8)$ & $192(8.8)$ & $41(7.2)$ & $9(9.0)$ & 88 (19.4) & \\
\hline Molecular subtype & & & & & & & $<0.01$ \\
\hline Luminal A & $2387(51.4)$ & $775(58.1)$ & $1122(51.5)$ & $267(46.6)$ & $32(32.0)$ & $191(42.2)$ & \\
\hline Luminal B & $535(11.5)$ & $144(10.8)$ & $246(11.3)$ & $72(12.6)$ & $18(18.0)$ & $55(12.1)$ & \\
\hline HER2 & $365(8.0)$ & 78 (5.9) & $178(8.2)$ & $67(11.7)$ & $11(11.0)$ & 31 (6.9) & \\
\hline Triple-negative & $517(11.1)$ & $130(9.7)$ & $241(11.1)$ & $81(14.1)$ & $10(10.0)$ & $55(12.1)$ & \\
\hline Unknown ${ }^{a}$ & $836(18.0)$ & $207(15.5)$ & 393 (18.0) & $86(15.0)$ & $29(29.0)$ & $121(26.7)$ & \\
\hline
\end{tabular}

Continuous data are expressed as mean \pm standard deviation (SD). Categorical data are expressed as number of cases (percent)

a Unknown data were not included in the statistical tests

b $P$ values were calculated using one-way analysis of variance (ANOVA) test (continuous variables) and Chi square or exact test (categorical variables) 
Table 2 Characteristics of breast cancer patients by molecular subtype

\begin{tabular}{|c|c|c|c|c|c|c|c|}
\hline \multirow[t]{2}{*}{ Characteristic } & \multirow[t]{2}{*}{ Overall } & \multicolumn{5}{|l|}{ Subtype } & \multirow[t]{2}{*}{$P$ value $^{\mathrm{b}}$} \\
\hline & & Luminal A & Luminal B & HER2 & Triple-negative & Unknown $^{a}$ & \\
\hline Total & 4640 & 2387 & 535 & 365 & 517 & 836 & \\
\hline Age (years) & $52.9 \pm 11.3$ & $53.5 \pm 11.8$ & $51.7 \pm 10.6$ & $52.9 \pm 10.1$ & $53.3 \pm 11.8$ & $53.2 \pm 11.8$ & 0.01 \\
\hline $\mathrm{BMI}$ & $25.0 \pm 3.8$ & $25.1 \pm 3.8$ & $24.6 \pm 3.8$ & $25.3 \pm 4.1$ & $24.9 \pm 3.7$ & $25.1 \pm 3.8$ & 0.07 \\
\hline Menopausal status & & & & & & & $<0.01$ \\
\hline Premenopausal & $2017(43.5)$ & $1085(45.5)$ & $241(45.1)$ & $129(35.3)$ & $205(39.7)$ & $357(42.7)$ & \\
\hline Postmenopausal & $2510(54.1)$ & $1251(52.4)$ & $280(52.3)$ & $232(63.6)$ & $303(58.6)$ & $444(53.1)$ & \\
\hline Unknown a & $113(2.4)$ & $51(2.1)$ & $14(2.6)$ & $4(1.1)$ & $9(1.7)$ & $35(4.2)$ & \\
\hline Histological grade & & & & & & & $<0.01$ \\
\hline Well differentiated & $349(7.5)$ & $227(9.5)$ & $24(4.5)$ & $12(3.3)$ & $18(3.5)$ & $68(8.1)$ & \\
\hline Moderately differentiated & $2549(54.9)$ & $1414(59.2)$ & $319(59.6)$ & $180(49.3)$ & $207(40.0)$ & $429(51.3)$ & \\
\hline Poorly differentiated & $899(19.4)$ & $306(12.8)$ & $131(24.5)$ & $124(34.0)$ & $193(37.3)$ & $145(17.4)$ & \\
\hline Unknown a & $843(18.2)$ & $440(18.4)$ & $61(11.4)$ & $49(13.4)$ & $99(19.2)$ & $194(23.2)$ & \\
\hline Histological type & & & & & & & $<0.01$ \\
\hline Ductal & $4031(86.9)$ & $2052(86.0)$ & $496(92.7)$ & $338(92.6)$ & $445(86.1)$ & $700(83.7)$ & \\
\hline Lobular & $149(3.2)$ & $100(4.2)$ & $8(1.5)$ & $3(0.8)$ & $9(1.7)$ & $29(3.5)$ & \\
\hline Others & $460(9.9)$ & $235(9.8)$ & $31(5.8)$ & $24(6.6)$ & $63(12.2)$ & $107(12.8)$ & \\
\hline Stage & & & & & & & $<0.01$ \\
\hline I & $1334(28.7)$ & $775(32.5)$ & $144(26.9)$ & $78(21.4)$ & $130(25.2)$ & $207(24.7)$ & \\
\hline$\|$ & $2180(47.0)$ & $1122(47.0)$ & $246(46.0)$ & $178(48.8)$ & $241(46.6)$ & $393(47.0)$ & \\
\hline III & $573(12.3)$ & $267(11.2)$ & $72(13.5)$ & $67(18.4)$ & $81(15.7)$ & $86(10.3)$ & \\
\hline IV & $100(2.2)$ & $32(1.3)$ & $18(3.4)$ & $11(3.0)$ & $10(1.9)$ & $29(3.5)$ & \\
\hline Unknown ${ }^{a}$ & $453(9.8)$ & $191(8.0)$ & $55(10.3)$ & $31(8.5)$ & 55 (10.6) & $121(14.5)$ & \\
\hline
\end{tabular}

Continuous data are expressed as mean \pm SD. Categorical data are expressed as number of cases (percent)

a Unknown data were not included in the statistical tests

b $P$ values were calculated using one-way ANOVA test (continuous variables) and Chi square or exact test (categorical variables)

89.4\% (95\% confidence interval [CI] 88.5\%-90.3\%), and the 5-year CSS rate was $90.3 \%$ (95\% CI 89.4\%-91.1\%) for all the patients. Both OS and CSS differed significantly by stage and molecular subtype (all $P<0.01$ ).

For patients with stage I, II, III, and IV breast cancer, the 5 -year OS rates were $96.5 \%, 91.6 \%, 74.8 \%$, and $40.7 \%$, respectively (Fig. 1a); the 5-year CSS rates were $97.1 \%$, $92.6 \%, 75.6 \%$, and $42.7 \%$, respectively (Fig. 1b). Patients with late-stage disease had much lower 5-year survival rates than those with early-stage disease (Table 3).

For patients with luminal A, luminal B, HER2, and triple-negative subtypes of breast cancer, the 5-year OS rates were $92.6 \%, 88.4 \%, 83.6 \%$, and $82.9 \%$, respectively (Fig. 1c); the 5-year CSS rates were 93.2\%, 89.1\%, 85.4\%, and $83.5 \%$, respectively (Fig. 1d). Patients with HER2 and triple-negative subtype tumors had lower survival rate than those with luminal A and luminal B subtype tumors (Table 4).

\section{Multivariate Cox regression analysis}

Multivariate Cox regression analysis (Table 5) showed that age was an independent prognostic factor for OS and
CSS. High BMI was associated with short OS, whereas no significant association was observed between BMI and CSS $(P=0.14)$. Patients with poorly differentiated tumor had shorter survival than those with well differentiated tumor. OS and CSS were significantly shorter among women with HER2 and triple-negative subtypes than those with luminal A subtype. Compared with patients at stage I, patients at stages II, III, and IV had significantly shorter OS and CSS.

\section{Discussion}

The present study demonstrated the influences of stage at diagnosis and molecular subtype on the survival of breast cancer patients with a large sample size. We found that survival varied significantly by stage at diagnosis and molecular subtype. Patients with late-stage disease had much lower survival rates than those with early-stage disease; patients with HER2 and triple-negative subtype tumors had lower survival rates than those with Luminal A or Luminal B subtype tumors.

The overall 5-year CSS rate in the present study was $90.3 \%$, which was much higher than the estimates around 

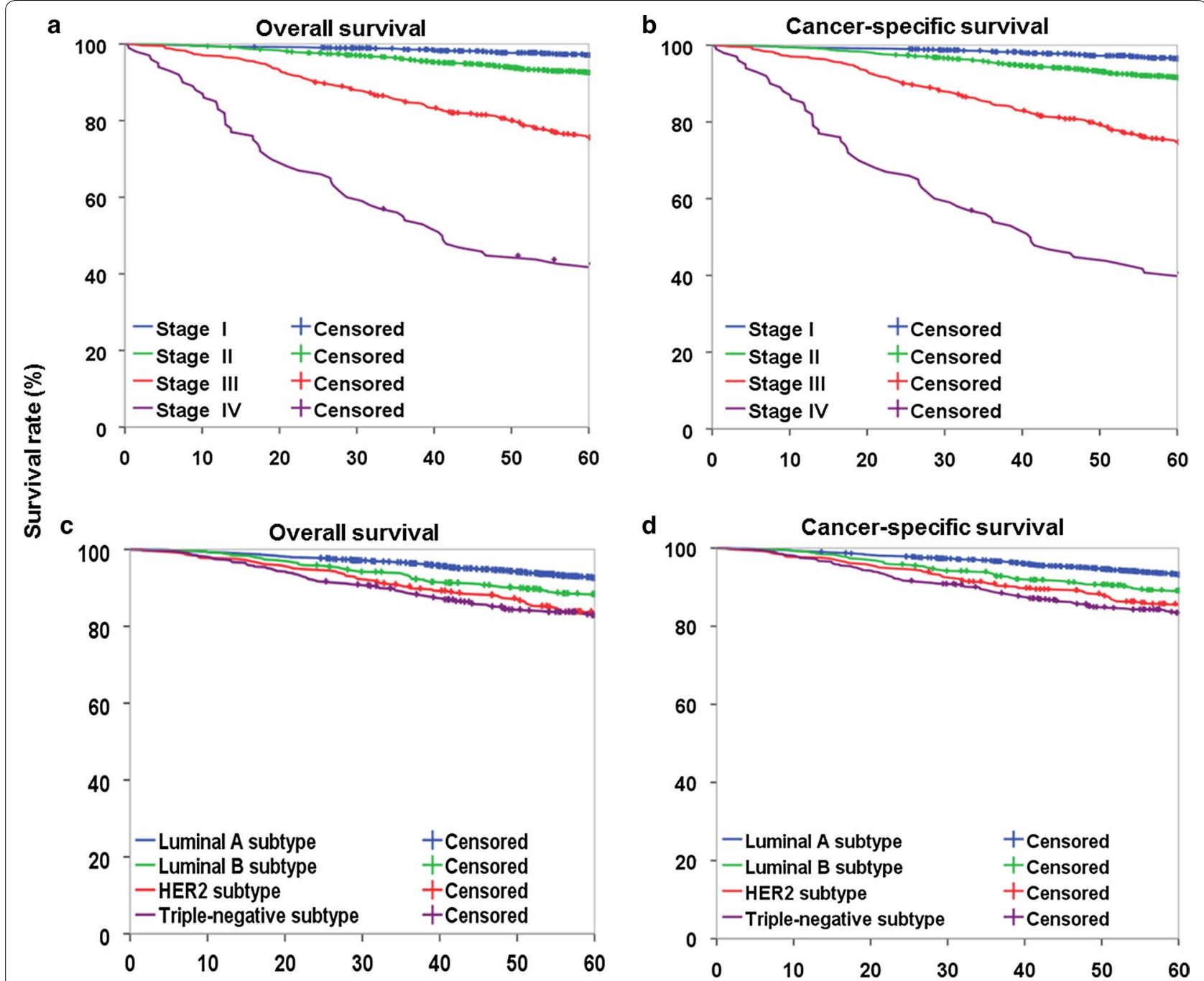

Time after diagnosis (months)

Fig. 1 Survival curves of female patients with breast cancer at different stages at diagnosis or of different molecular subtypes. a Overall survival curves of patients according to tumor stage. b Cancer-specific survival curves of patients according to tumor stage. c Overall survival curves of patients according to molecular subtype. $\mathbf{d}$ Cancer-specific survival curves of patients according to molecular subtype. Log-rank test showed significant differences in survival among groups in the four panels (all $P<0.01$ )

China [16], while similar to those in developed countries. The relative survival estimates were $89.7 \%$ in the United States (2007-2013) [17] and 89.8\% in Australia (20082012) [18]. As one of the largest cities and the capital of China, Beijing has more advanced medical facilities and health resources than most of other cities in China [19]. Patients diagnosed with breast cancer in Beijing could receive better supportive care and expect more favorable treatment outcome. These may all together contribute to the similar breast cancer patient survival rates between Beijing and developed countries.

Stage at diagnosis is a key prognostic factor of breast cancer $[20,21]$. In western countries such as Canada,
Denmark, Norway, Sweden, and the United Kingdom, about $30.1 \%-45.2 \%$ patients were diagnosed with stage I, $39.0 \%-47.7 \%$ with stage II, $3.5 \%-15.3 \%$ with stage III, and $2.9 \%-6.9 \%$ with stage IV diseases [20]. Our population showed a higher proportion of stage III and stage IV diseases compared with those in European countries such as Norway, Sweden, and the United Kingdom, which may plead for enforced screening program for primary prevention. Considering most of the hospitals involved in our study are tertiary-level medical institutions and a portion of stage IV breast cancer patients diagnosed at relatively low-level hospitals did not receive effective treatment or adopted conservative treatment, 





Table 4 Survival of patients with breast cancer according to different stages and molecular subtypes

\begin{tabular}{|c|c|c|}
\hline Characteristic & $\begin{array}{l}\text { 5-year OS rate } \\
{[\%(95 \% \mathrm{Cl})]}\end{array}$ & $\begin{array}{l}\text { 5-year CSS rate } \\
{[\%(95 \% \mathrm{Cl})]}\end{array}$ \\
\hline Overall & $89.4(88.5-90.3)$ & $90.3(89.4-91.1)$ \\
\hline \multicolumn{3}{|l|}{ Stage } \\
\hline 1 & $96.5(95.4-97.4)$ & $97.1(96.1-97.9)$ \\
\hline$\|$ & $91.6(90.3-92.7)$ & $92.6(91.4-93.6)$ \\
\hline III & $74.8(71.0-78.2)$ & $75.6(71.8-78.9)$ \\
\hline IV & $40.7(31.0-50.1)$ & $42.7(32.8-52.1)$ \\
\hline \multicolumn{3}{|l|}{ Molecular subtype } \\
\hline Luminal A & $92.6(91.5-93.6)$ & $93.2(92.1-94.2)$ \\
\hline Luminal B & $88.4(85.3-90.9)$ & $89.1(86.1-91.5)$ \\
\hline HER2 & $83.6(79.3-87.0)$ & $85.4(81.3-88.7)$ \\
\hline Triple-negative & 82.9 (79.3-85.9) & 83.5 (79.9-86.4) \\
\hline
\end{tabular}

OS overall survival, CSS cancer-specific survival, Cl confidence interval

the proportion of patients with stage IV disease in the present study may be lower compared with the figure in actual population.
Compared with the reported survival rates in two periods in Beijing, 66.3\% (1982-1983) and 74.2\% (19871988) [22], the survival rate of breast cancer patients was remarkably increased in the present study. The improvement in treatment may contribute to the prolonged survival over the past decades [23, 24]. Besides, with the development of economy and society, citizens may have better awareness on health and early diagnosis of breast cancer. A better stage distribution between 2006 and 2010 compared with those in the past decades may also be an important contributor to the prolonged survival. People living in Beijing are more likely to have high socioeconomic status, to be literal on health, and to have access to good medical service to detect precancerous lesions compared with those in most other cities in China. Precancerous lesions in the breast have visible symptoms with favorable prognosis. An amount of women would go to the hospital when they found palpable masses in the breast. Besides, women in Beijing will easily have access to knowledge on cancer prevention which in turn enhances their awareness on self-exams. Clinical breast examinations, including mammography

Table 5 Multivariate analysis of overall survival and cancer-specific survival using Cox proportion hazards modeling

\begin{tabular}{|c|c|c|c|c|}
\hline \multirow[t]{2}{*}{ Characteristic } & \multicolumn{2}{|l|}{ os } & \multicolumn{2}{|l|}{ CSS } \\
\hline & $\mathrm{HR}^{\mathrm{a}}(95 \% \mathrm{Cl})$ & $P$ value $^{\mathrm{a}}$ & $\mathrm{HR}^{\mathrm{a}}(95 \% \mathrm{Cl})$ & $P$ value $^{\mathrm{a}}$ \\
\hline Age & $1.03(1.02-1.05)$ & $<0.01$ & $1.03(1.01-1.04)$ & 0.01 \\
\hline BMI & $1.03(1.01-1.06)$ & 0.02 & $1.02(0.99-1.05)$ & 0.14 \\
\hline \multicolumn{5}{|l|}{ Menopausal status } \\
\hline Premenopausal & 1.00 & & 1.00 & \\
\hline Postmenopausal & $0.80(0.59-1.09)$ & 0.16 & $0.81(0.58-1.12)$ & 0.21 \\
\hline \multicolumn{5}{|l|}{ Histological grade } \\
\hline Well differentiated & 1.00 & & 1.00 & \\
\hline Moderately differentiated & $1.60(0.94-2.71)$ & 0.08 & $1.50(0.87-2.59)$ & 0.14 \\
\hline Poorly differentiated & $2.14(1.24-3.70)$ & 0.01 & $2.02(1.15-3.55)$ & 0.02 \\
\hline \multicolumn{5}{|l|}{ Histological type } \\
\hline Ductal & 1.00 & & 1.00 & \\
\hline Lobular & $0.91(0.33-2.46)$ & 0.85 & $0.77(0.24-2.44)$ & 0.66 \\
\hline Others & $0.94(0.56-1.59)$ & 0.83 & $0.85(0.48-1.52)$ & 0.59 \\
\hline \multicolumn{5}{|l|}{ Stage } \\
\hline । & 1.00 & & 1.00 & \\
\hline$\|$ & $2.19(1.57-3.06)$ & $<0.01$ & $2.24(1.56-3.22)$ & $<0.01$ \\
\hline III & $6.24(4.40-8.87)$ & $<0.01$ & $6.89(4.72-10.05)$ & $<0.01$ \\
\hline IV & $25.77(16.36-40.59)$ & $<0.01$ & $29.48(18.33-47.44)$ & $<0.01$ \\
\hline \multicolumn{5}{|l|}{ Molecular subtype } \\
\hline Luminal A & 1.00 & & 1.00 & \\
\hline Luminal B & $1.26(0.93-1.72)$ & 0.14 & $1.31(0.95-1.80)$ & 0.10 \\
\hline HER2 & $1.50(1.08-2.09)$ & 0.02 & $1.47(1.03-2.09)$ & 0.03 \\
\hline Triple-negative & $1.83(1.37-2.43)$ & $<0.01$ & $1.89(1.39-2.55)$ & $<0.01$ \\
\hline
\end{tabular}

${ }^{\mathrm{a}} \mathrm{HRs}, 95 \% \mathrm{Cls}$, and $P$ values were calculated using the adjusted multivariate Cox proportional hazard model OS overall survival, CSS cancer-specific survival, $H R$ hazard ratio, $\mathrm{Cl}$ confidence interval, $B M I$ body mass index 
and ultrasound, are vital approaches to an early diagnosis of the disease. Since 2008, breast cancer screening was performed in Beijing for resident women aged 40-60 years. In addition, since 2011, a biennial breast screening program, free of charge, has been launched in Beijing for women aged 35-64 years [25]. Moreover, awareness campaigns have been carried out in communities in turn to inform and educate people on the disease. It is expected that the survival of breast cancer patients in Beijing would be further prolonged in the future. Breast cancer screening programs have been implemented in developed countries for years [26, 27]. The United States Prevention Services Task Force (USPSTF) recommended biennial mammography screening for women aged 50-74 years and selective screening for those aged 40-49 years [27]. The international agency for research on cancer (IARC) have concluded that breast cancer mortality is generally reduced by screening especially for women aged 50-69 years [28]. However, there is no nationwide breast cancer screening program in China. Chinese women tend to have dense breasts [29], which have low sensitivity and specificity in mammography screening [30]. Ultrasound is a better choice for screening and showed higher efficacy on identifying early-stage patients than mammography from high-risk Chinese women [31]. Moreover, the uneven distribution of health care resources and services make it difficult to carry out uniform screening method in China. Spatio-temporal analysis revealed the cluster pattern for the incidence of female breast cancer, which was useful for a better allocation of health care resources [32]. Large randomized controlled trials of population-based studies are in urgent need among the Chinese population.

Breast cancer is a heterogeneous disease with different molecular subtypes. Our study enabled us to further examine the subtypes of the disease and their associations with survival. The proportion of HER2 subtype in the Chinese population is relatively higher than that for whites in the US, and the proportion of triple-negative subtype is lower than that for African Americans [33], which is consistent with the published findings that the proportion of HER2 subtype was higher in Asian and the triple-negative subtype was more frequent in Black [34].

Significant survival disparities were observed between hormone receptor-positive tumors (luminal A and luminal B) and hormone receptor-negative tumors (triple-negative and HER2). Breast cancer is a hormone-dependent cancer. ER-positive or PR-positive tumors account for the majority of breast cancers diagnosed. The survival differences among patients with various molecular subtypes of breast cancer reflected the distinct treatment responses associated with different expression statuses of hormone receptors. Tamoxifen and aromatase inhibitors are routine drugs for hormone receptor-positive tumors, and patients with HER2-overexpressed tumors can be treated with trastuzumab [35-37]. Triple-negative tumors can only be treated with surgery, radiation therapy, and/ or chemotherapy [38]. Survival of patients with HER2 subtype disease was similar to that of patients with triplenegative subtype disease in the present study. The reason may be due to the insufficient use of targeted drugs for patients with HER2-deficient tumors [39]. The targeted drugs can be a large financial burden for the patients and are not covered by the basic medical insurances for urban residents and the new-rural cooperative medical system insurance in Beijing. Furthermore, not all HER2-positive breast cancer patients can benefit from trastuzumab therapy [40]. Therefore, the improving health insurance coverage may be needed. More advanced therapies and health care policies on HER2 and triple-negative molecular subtypes are of great importance.

BMI and histological grade are significant indicators associated with breast cancer patient survival apart from stage at diagnosis and molecular subtype, which had been reported in previous studies [41, 42]. Application of BMI and histological grade in the clinical practice can help clinicians predict the prognosis of breast cancer patients. Besides, relative studies showed that early age at menarche, late age at menopause, nulliparity, late age at first birth, and limited breastfeeding were also associated with increased risk of breast cancer in Chinese [43]. Activities on promoting the awareness of risk factors in women may improve the cognition of breast cancer, which could help women in risk pay more attention on cancer detection or recognize the disease in early stage.

The Beijing cancer registry was established in 1976, which has a long history and good working basis on cancer incidence and mortality registration in China. Considering some breast cancer patients were lack of effective treatment in the population, the 5-year CSS rate in Beijing in the present study may be higher than that of population-based estimates. However, the multicenter nature of the study enables an inclusion of about $40 \%$ of the total patient population, which leads to a fair degree of external generalizability of the survival estimates of patients with breast cancer at different stages and of different molecular subtypes. Hospital-based cancer registration can provide extensive, detailed, and reliable information on clinical characteristics. As hormone receptor status and cancer stage are not routinely required by registries, limited high-resolution survival researches in China hindered the cognition of breast cancer and the development of its treatment. This study can help explore hospital-based cancer registration pattern, assess data accessibility, and provide basic information for evidence-based medicine. 


\section{Conclusions}

The present study demonstrated the influences of stage at diagnosis and molecular subtype on the survival of breast cancer patients with a large sample size. Stage at diagnosis and molecular subtype are independent prognostic factors associated with breast cancer patient survival. Patients with late-stage diseases had much lower survival rates than those with early-stage diseases, and patients with HER2 or triple-negative subtype tumors had lower survival rates than those with luminal $\mathrm{A}$ or luminal B subtype tumors. Cancer screening is encouraged for the early detection and early diagnosis of breast cancer. More advanced therapies and health care policies are needed on HER2 and triple-negative subtypes. Our study can also provide basic information for clinicians and policy-makers in further actions on breast cancer treatment research and health care and serve as a baseline for the establishment of hospital-based cancer registration system.

\section{Abbreviations}

OS: overall survival; CSS: cancer-specific survival; BMI: body mass index; ER: estrogen receptor; PR: progesterone receptor; HER2: human epidermal growth factor 2; FISH: fluorescence in situ hybridization; HR: hazard ratio; $\mathrm{Cl}$ : confidence interval; USPSTF: US Prevention Services Task Force; IARC: International Agency for Research on Cancer; ANOVA: analysis of variance; SD: standard deviation.

\section{Authors' contributions}

ZTT cleared up the data and wrote the manuscript. ZHM and CWQ contributed to the conception and design of the study proposal. ZTT, LHC, LS, YL, and XCF collected the clinical data from hospital medical records. ZTT and ZRS performed data analysis and interpretation. ZHM, LLF, and CWQ revised the manuscript. MF, WN, and XLX reviewed the manuscript and provided suggestions. All authors read and approved the final manuscript.

\section{Author details \\ ${ }^{1}$ National Office for Cancer Prevention and Control \& National Central Cancer Registry, National Cancer Center/Cancer Hospital, Chinese Academy of Medical Sciences and Peking Union Medical College, Beijing 100021, P. R. China. ${ }^{2}$ Key Laboratory of Carcinogenesis and Translation Research (Ministry of Education/Beijing), Beijing Office for Cancer Prevention and Control, Peking University Cancer Hospital \& Institute, Beijing 100142, P. R. China. ${ }^{3}$ Department of Medical Oncology, National Cancer Center/Cancer Hospital, Chinese Acad- emy of Medical Sciences and Peking Union Medical College, Beijing 100021, P. R. China. ${ }^{4}$ Department of Statistics, The European Organization for Research and Treatment of Cancer (EORTC), 111200 Brussels, Belgium. ${ }^{5}$ Department of Breast Surgery, National Cancer Center/Cancer Hospital, Chinese Academy of Medical Sciences and Peking Union Medical College, Beijing 100021, P. R. China.}

\section{Acknowledgements}

We gratefully acknowledge the cooperation of all participating hospitals and the team of Beijing cancer registry for data collection.

This work was supported by the Beijing Natural Science Foundation (No. 7142139); the CAMS Innovation Fund for Medical Sciences (CIFMS) (No. 2016-12M-2-004); the PUMC Youth Fund/Fundamental Research Funds for the Central Universities (No. 3332016033); and the National Key Research Program of China (No. 2016YFC1302502).

\section{Competing interests}

The authors declare that they have no competing interests.

\section{Availability of data and materials}

All the data supporting the conclusions of this article are included in the article.

\section{Consent for publication \\ Not applicable.}

\section{Ethics approval and consent to participate}

The study protocol was approved by the Independent Ethics Committee of National Good Clinical Practice (GCP) Center for Anticancer Drugs in Cancer Hospital, Chinese Academy of Medical Sciences. This is a retrospective study that we collected clinical information from medical records instead of face-toface investigation, so that consent to participate was waived.

Received: 4 May 2017 Accepted: 16 July 2017

Published online: 25 October 2017

\section{References}

1. Chen WQ, Zheng RS, Baade PD, Zhang SW, Zeng HM, Bray F, et al. Cancer statistics in China, 2015. CA Cancer J Clin. 2016;66(2):115-32.

2. Chen WQ, Zheng RS, Zeng HM, Zhang SW. The incidence and mortality of major cancers in China, 2012. Chin J Cancer. 2016;35(1):73.

3. Yang L, Yuan YN, Sun TT, Li HC, Wang N. Population-based cancer incidence analysis in Beijing, 2008-2012. Chin J Cancer Res. 2015;27(1):13-21.

4. Li L, Ji J, Wang JB, Niyazi M, Qiao YL, Boffetta P. Attributable causes of breast cancer and ovarian cancer in China: reproductive factors, oral contraceptives and hormone replacement therapy. Chin J Cancer Res. 2012;24(1):9-17.

5. Goss PE, Strasser-Weippl K, Lee-Bychkovsky BL, Fan L, Li J, Chavarri-Guerra $Y$, et al. Challenges to effective cancer control in China, India, and Russia. Lancet Oncol. 2014;15(5):489-538.

6. Yang $L$, Sun TT, Wang N. The incidence and mortality trends of female breast cancer in Beijing, China: between 2004 and 2008. Zhonghua Yu Fang Yi Xue Za Zhi. 2012;46(11):1009-14 (in Chinese).

7. Sant M, Allemani C, Capocaccia R, Hakulinen T, Aareleid T, Coebergh JW, et al. Stage at diagnosis is a key explanation of differences in breast cancer survival across Europe. Int J Cancer. 2003;106(3):416-22.

8. Allemani C, Sant M, Weir HK, Richardson LC, Baili P, Storm H, et al. Breast cancer survival in the US and Europe: a CONCORD high-resolution study. Int J Cancer. 2013;132(5):1170-81.

9. Prat A, Pineda E, Adamo B, Galvan P, Fernandez A, Gaba L, et al. Clinical implications of the intrinsic molecular subtypes of breast cancer. Breast. 2015;24(Suppl 2):S26-35.

10. Cancer Genome Atlas. N. Comprehensive molecular portraits of human breast tumours. Nature. 2012;490(7418):61-70.

11. Zhao J, Liu H, Wang M, Gu L, Guo X, Gu F, et al. Characteristics and prognosis for molecular breast cancer subtypes in Chinese women. J Surg Oncol. 2009;100(2):89-94.

12. Xue C, Wang X, Peng R, Shi Y, Qin T, Liu D, et al. Distribution, clinicopathologic features and survival of breast cancer subtypes in Southern China. Cancer Sci. 2012;103(9):1679-87.

13. Su Y, Zheng Y, Zheng W, Gu K, Chen Z, Li G, et al. Distinct distribution and prognostic significance of molecular subtypes of breast cancer in Chinese women: a population-based cohort study. BMC Cancer. 2011;11:292.

14. Edge SB, Compton CC. The American Joint Committee on Cancer: the 7th edition of the AJCC cancer staging manual and the future of TNM. Ann Surg Oncol. 2010;17(6):1471-4.

15. Anderson WF, Rosenberg PS, Katki HA. Tracking and evaluating molecular tumor markers with cancer registry data: HER2 and breast cancer. J Natl Cancer Inst. 2014;106(5):dju093.

16. Zeng HM, Zheng RS, Guo YM, Zhang SW, Zou XN, Wang N, et al. Cancer survival in China, 2003-2005: a population-based study. Int J Cancer. 2015;136(8):1921-30

17. Howlader N, Noone AM, Krapcho M, Miller D, Bishop K, Kosary CL, et al. SEER Cancer Statistics Review, 1975-2014, National Cancer Institute. https://seer.cancer.gov/csr/1975_2014/. Accessed 18 Apr 2017.

18. Australian Institute of Health and Welfare. Breast cancer in Australia. http://www.aihw.gov.au/cancer/breast/. Accessed 7 Mar 2017. 
19. Hou Y, Chen XY. China health statistics yearbook of 2013. Beijing: People's Medical Publishing House; 2014

20. Walters S, Maringe C, Butler J, Rachet B, Barrett-Lee P, Bergh J, et al. Breast cancer survival and stage at diagnosis in Australia, Canada, Denmark, Norway, Sweden and the UK, 2000-2007: a population-based study. Br J Cancer. 2013;108(5):1195-208.

21. DeSantis CE, Fedewa SA, Sauer AG, Kramer JL, Smith RA, Jemal A. Breast cancer statistics, 2015: convergence of incidence rates between black and white women. CA Cancer J Clin. 2016;66(1):31-42.

22. Wang QJ, Zhu WX, Xing XM. Analysis of the incidence and survival of female breast cancer in Beijing during the last 20 years. Zhonghua Zhong Liu Za Zhi. 2006;28:208-10 (in Chinese)

23. Harbeck N, Gnant M. Breast cancer. Lancet. 2017;389(10074):1134-50

24. Li J, Zhang BN, Fan JH, Pang Y, Zhang P, Wang SL, et al. A nation-wide multicenter 10-year (1999-2008) retrospective clinical epidemiological study of female breast cancer in China. BMC Cancer. 2011;11:364.

25. Zhang BN. Thinking caused by the dispute of international breast cancer screening guidelines. Oncol Prog. 2016;14(2):109-11 (in Chinese).

26. de Waard F, Kirkpatrick A, Perry NM, Tornberg S, Tubiana M, de Wolf C. Breast cancer screening in the framework of the Europe against Cancer programme. Eur J Cancer Prev. 1994;3(Suppl 1):3-5.

27. US Preventive Services Task Force. Screening for breast cancer: US Preventive Services Task Force recommendation statement. Ann Intern Med. 2009;151(10):716-26 (W-236)

28. Nelson HD, Fu R, Cantor A, Pappas M, Daeges M, Humphrey L. Effectiveness of breast cancer screening: systematic review and meta-analysis to update the 2009 US Preventive Services Task Force Recommendation. Ann Intern Med. 2016;164(4):244-55.

29. Zulfiqar M, Rohazly I, Rahmah M. Do the majority of Malaysian women have dense breasts on mammogram? Biomed Imaging Interv J. 2011;7(2):e14

30. Melnikow J, Fenton JJ, Whitlock EP, Miglioretti DL, Weyrich MS, Thompson $\mathrm{H}$, et al. Supplemental screening for breast cancer in women with dense breasts: a systematic review for the US Preventive Services Task Force. Ann Intern Med. 2016;164(4):268-78.

31. Shen $S$, Zhou Y, Xu Y, Zhang B, Duan X, Huang R, et al. A multicentre randomised trial comparing ultrasound vs mammography for screening breast cancer in high-risk Chinese women. Br J Cancer. 2015;112(6):998-1004
32. Zhou HB, Liu SY, Lei L, Chen ZW, Peng J, Yang TZ, et al. Spatio-temporal analysis of female breast cancer incidence in Shenzhen, 2007-2012. Chin Cancer. 2015;34(5):198-204

33. O'Brien KM, Cole SR, Tse CK, Perou CM, Carey LA, Foulkes WD, et al. Intrinsic breast tumor subtypes, race, and long-term survival in the Carolina Breast Cancer Study. Clin Cancer Res. 2010;16(24):6100-10.

34. Warner ET, Tamimi RM, Hughes ME, Ottesen RA, Wong YN, Edge SB, et al. Racial and ethnic differences in breast cancer survival: mediating effect of tumor characteristics and sociodemographic and treatment factors. J Clin Oncol. 2015;33(20):2254-61.

35. Platet N, Cathiard AM, Gleizes M, Garcia M. Estrogens and their receptors in breast cancer progression: a dual role in cancer proliferation and invasion. Crit Rev Oncol Hematol. 2004;51 (1):55-67.

36. Piccart-Gebhart MJ, Procter M, Leyland-Jones B, Goldhirsch A, Untch M, Smith I, et al. Trastuzumab after adjuvant chemotherapy in HER2-positive breast cancer. N Engl J Med. 2005;353(16):1659-72.

37. Buzdar AU. Aromatase inhibitors: changing the face of endocrine therapy for breast cancer. Breast Dis. 2005:24:107-17.

38. Cleator S, Heller W, Coombes RC. Triple-negative breast cancer: therapeutic options. Lancet Oncol. 2007:8(3):235-44.

39. Yuan XM, Wang N, Ouyang T, Yang L, Song MY, Lin BY, et al. Current status of diagnosis and treatment of primary breast cancer in beijing, 2008. Chin J Cancer Res. 2011;23(1):38-42.

40. Vogel CL, Cobleigh MA, Tripathy D, Gutheil JC, Harris LN, Fehrenbacher $L$, et al. Efficacy and safety of trastuzumab as a single agent in first-line treatment of HER2-overexpressing metastatic breast cancer. J Clin Oncol. 2002:20(3):719-26.

41. Holleczek B, Brenner H. Provision of breast cancer care and survival in Germany-results from a population-based high resolution study from Saarland. BMC Cancer. 2014;14:757.

42. Chan DS, Vieira AR, Aune D, Bandera EV, Greenwood DC, McTiernan A, et al. Body mass index and survival in women with breast cancer-systematic literature review and meta-analysis of 82 follow-up studies. Ann Oncol. 2014;25(10):1901-14.

43. Fan L, Strasser-Weippl K, Li JJ, St Louis J, Finkelstein DM, Yu KD, et al. Breast cancer in China. Lancet Oncol. 2014;15(7):e279-89.

\section{Submit your next manuscript to BioMed Central and we will help you at every step:}

- We accept pre-submission inquiries

- Our selector tool helps you to find the most relevant journal

- We provide round the clock customer support

- Convenient online submission

- Thorough peer review

- Inclusion in PubMed and all major indexing services

- Maximum visibility for your research

Submit your manuscript at www.biomedcentral.com/submit
BioMed Central 